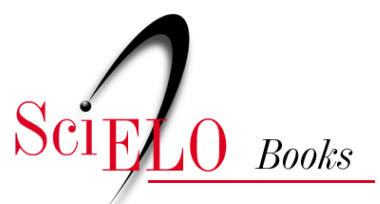

\title{
Introdução \\ Celso Furtado: um militante da esperança
}

\author{
Cidoval Morais de Sousa \\ Ivo Marcos Theis \\ José Luciano Albino Barbosa
}

\section{SciELO Books / SciELO Livros / SciELO Libros}

SOUSA, C. M., THEIS, I. M., and BARBOSA, J. L. A., eds. Introdução Celso Furtado: um militante da esperança. In: Celso Furtado: a esperança militante (Interpretações): vol. 1 [online]. Campina Grande: EDUEPB, 2020, pp. 17-34. Projeto editorial 100 anos de Celso Furtado collection. ISBN: 978-65-86221-08-4. https://doi.org/10.7476/9786586221695.0002.

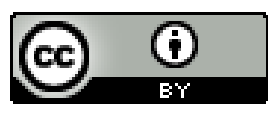

All the contents of this work, except where otherwise noted, is licensed under a Creative Commons Attribution 4.0 International license.

Todo o conteúdo deste trabalho, exceto quando houver ressalva, é publicado sob a licença Creative Commons Atribição 4.0.

Todo el contenido de esta obra, excepto donde se indique lo contrario, está bajo licencia de la licencia Creative Commons Reconocimento 4.0. 


\title{
Introdução
}

\section{Celso Furtado: um militante da esperança}

\author{
Cidoval Morais de Sousa \\ Ivo Marcos Theis ${ }^{2}$ \\ José Luciano Albino Barbosa ${ }^{3}$
}

\section{Introdução}

Não parece restar dúvidas que Celso Furtado (1920-2004) foi um dos mais importantes economistas e cientistas sociais brasileiros. Sua obra atravessou o século XX e chegou ao século XXI agendando e provocando debates e proposições para a solução de problemas crônicos no Brasil, como as desigualdades regionais. Furtado é leitura obrigatória para aqueles que procuram compreender os liames sociais e econômicos que orientam o campo das alternativas e a construção de um projeto de País, característica marcante de seus escritos (CÊPEDA, 2001).

A intensidade com que a obra de Celso Furtado tem sido discutida e a sua permanência no tempo iluminando a produção tecnocientífica em diferentes campos (da Economia Política, passando pelas Ciências Sociais, Ciências da Saúde, Ciências Agrárias, até a Biologia) podem ser observadas em números que surpreendem nas principais bases de

1 Jornalista, Doutor em Geociências pela Unicamp, professor e pesquisador da Universidade Estadual da Paraíba (UEPB), vinculado aos Programas de Pós-graduação em Desenvolvimento Regional e Ensino de Ciências e Educação Matemática. Colabora com o PPGCTS da UFSCar.

2 Economista, PhD em Geografia Humana pela Eberhard-Karls Universität Tübinguen (Alemanha), docente pesquisador do Programa de Pós-graduação em Desenvolvimento Regional da Universidade Regional de Blumenau (FURB), líder de núcleo de pesquisa e editor da Revista Brasileira de Desenvolvimento Regional.

3 Sociólogo, Doutor em Sociologia pela UFPB, professor efetivo da Universidade Estadual da Paraíba (UEPB), vinculado ao Departamento de Ciências Sociais e docente permanente do Programa de Pós-graduação em Desenvolvimento Regional. 
gestão, indexação e divulgação dos periódicos científicos mais qualificados do Brasil e do mundo. Na base Scielo, por exemplo, no momento em que escrevemos, encontramos 88 publicações sobre a obra do economista paraibano, produzidos nos últimos 20 anos, em Países como Brasil, México, Venezuela, Chile, Colômbia e Portugal.

Se transferirmos a busca para o Portal de Periódicos da Capes, utilizando o mesmo descritor (Celso Furtado), o resultado é acachapante: são 1.257 textos, sendo 1.06o artigos revisados por pares, 125 resenhas e 43 livros. Desse total, 268 têm origem brasileira e concentram-se em temas como economia e desenvolvimento, neoliberalismo, política econômica, capitalismo e negócios. Furtado aparece como autor em 21 publicações, grande parte escrita em inglês. São 195 citações só no Science Index (Web of Science Group) - a mais importante base de mensuração de impacto de uma obra acadêmica no mundo.

Outro indicador importante do reconhecimento de Celso Furtado no panorama acadêmico mundial pode ser verificado no Google Acadêmico. Nossa busca, também com o mesmo descritor, obteve 44.300 resultados, ficando muito a frente de pensadores como Caio Prado Júnior (20.900) e Florestan Fernandes (29.900). Há, por outro lado, 6,8 milhões de referências ao economista quando a busca é feita no Google. Localizamos 13,7 mil notícias e mais de 80 mil vídeos, incluindo reprodução de entrevistas, documentários, programas e reportagens envolvendo, direta (com a presença dele) e indiretamente (sendo, por exemplo, tema da produção), o nosso homenageado.

O propósito desta coletânea, que reúne textos de mais de 20 pensadores brasileiros, latino-americanos e portugueses com forte inserção nacional e internacional, é celebrar os 100 anos de nascimento desse paraibano que se tornou um clássico do pensamento brasileiro e, sobretudo, um militante da esperança.

\section{Um Clássico}

Um pensamento clássico para assim ser considerado deve ser atual ao induzir compreensões sobre problemas cotidianos, segundo instrumentos originais de reflexão. Perdura no tempo por essa capacidade de se renovar. Estas são, em linhas gerais, as condições que o definem. No entanto, há outra face de igual importância para as obras inacabadas, quanto à análise e aos ensinamentos: a capacidade inventiva. De algum modo, talvez sem esta pretensão no momento em que foi criada, a obra 
clássica diz respeito àqueles arranjos argumentativos que abordam sobre a origem, sobre o que toca certeiro na identidade. Assim, algo de mitológico lhe assenta, tendo em vista ser aquela fonte cuja água nunca se acaba, e cujo norte sempre guia. Sua leitura, mesmo de outro tempo, de alguma forma tem o que dizer sobre o hodierno. Na vasta obra de Celso Furtado há quatro pilares que demonstram a sua dimensão clássica, quer dizer, aquilo que o coloca na condição de inventor do Nordeste, do Brasil.

Em primeiro lugar, dos anos 1950, com o GTDN (Grupo de Trabalho para o Desenvolvimento do Nordeste) até suas últimas falas, Furtado demonstrou o que significa a relação inseparável entre o pensar e o agir, entre o rigor acadêmico e o engajamento político. O esforço de uma vida esteve orientado para o enfrentamento dos problemas seculares do Brasil, para a superação de sua condição subdesenvolvida. Embora as terminologias sejam outras nos dias atuais, além do Brasil ter avançado bastante, a questão colocada por ele dizia respeito a algo atualíssimo: a renovada capacidade de gerar riqueza na mesma proporção em que se acumula. As tentativas de mudança desse "defeito" de origem culminam sempre em golpes. Este é o ponto central no pensamento de Furtado, a questão do subdesenvolvimento.

Segundo, em relação ao Nordeste, pela primeira vez, ataca-se o problema pela dimensão econômica, política, sociológica, e não pelas batidas teclas do combate à seca com a construção de açudes e frentes de emergência. Furtado antropologizou o problema. A questão fundamental seria romper com as estruturas arcaicas, como o coronelismo. Deveriam ser atacadas as formas de exploração do homem e da terra, substituindo isso tudo pelo que havia de mais atual, que era, nos anos de 1950, o desenvolvimento pela geração de renda através da industrialização e do consequente emprego formal. Não havia, no seu entender, como mudar o Brasil sem resolver o problema do Nordeste, sem atacar nossas formas de exclusão.

Em terceiro, promover o desenvolvimento não diz respeito a fórmulas mágicas ou a projetos de gênios extraordinários. Refere-se, por outro lado, à capacidade de planejamento, a arranjos burocráticos e institucionalizados que garantam a reprodução controlada de novas práticas de gestão. Em resumo, o desenvolvimento está no plano econômico, na transformação social pela geração de riqueza e renda, mas isso precisa ocorrer em meio a instituições democráticas que assegurem o que hoje se chama de desenvolvimento sustentável. Para Furtado, o Estado 
Democrático assume o protagonismo nesse contexto, sendo, assim, o grande articulador de forças e potencialidades para a condução de uma economia integrada, com redução das desigualdades regionais, bem diferente dos ciclos econômicos (pau-brasil, cana-de-açúcar, cacau, ouro, café etc.), queao tempo em que geram riqueza, ampliam as desigualdades.

Por último, rompe com o complexo de vira-latas. Na esteira do que foi o governo JK, Furtado se enche de esperança para tornar o Brasil uma grande nação: rica, soberana, menos desigual. Assim, sua obra traz consigo a crítica, a análise dos problemas sociais, mas, sobretudo, o destaque de nossas potencialidades. No caso do Nordeste isto fica muito claro. Enquanto os outros exemplos de intervenção se referiam à região como problema, como flagelo, em Furtado tal problema era diagnosticado no sentido de sua superação, não como um lugar de coitados a mendigar esmolas aos centros ricos. A partir dele, nenhum nordestino e brasileiro deve se colocar na condição de vira-latas, de (sub)alguma coisa. As dificuldades devem sinalizar para sua superação e o Nordeste era e é isto, um infindável complexo de potencialidades econômicas, sociais, culturais, de riqueza incalculável. Em Furtado há uma fonte de esperança, devidamente demonstrada, de que podemos ser mais. Podemos dizer que ele carrega, e isto se faz presente na obra, aquele ímpeto civilizatório do Pós-Segunda Guerra Mundial. Não mais 'o país do futuro', mas uma nação como projeto.

São esses elementos que o definem como um pensador clássico brasileiro, e que são melhor compreendidos quando focamos a lupa para algo anterior a isso tudo. Estamos nos referindo a questões existenciais que foram determinantes para toda a sua trajetória como homem das letras e da ação. Da infância em Pombal, na Paraíba, ao jovem da Força Expedicionário Brasileira, Furtado foi forjado entre guerras. Seja a situação trágica do sertão paraibano, seja diante do cenário destrutivo provocado pela Segunda Grande Guerra Mundial. Não foi ele um retórico, um pensador de gabinete. Da mesma forma que presenciou a reconstrução da Europa, imaginou para o Nordeste e para o Brasil algo semelhante.

Este era Celso Furtado, um homem educado pelas letras e pela pedra - como diz João Cabral de Melo Neto. De Sorbonne e de Sertão, alguém que sempre esteve diante de crises, a estudá-las de frente, encontrando suas causas históricas e propondo soluções racionais, viáveis diante do razoável e possível. Ele tinha 'a pedra de nascença do sertão, entranhada', cuja sorte nunca a removeu, de 'carnadura concreta' que o definiu como 
inquieto ao enfrentamento das contradições do Nordeste. Foi um cangaceiro das letras.

Neste contexto de profunda crise (Covid-19), ler Furtado está na ordem do dia. Mais do que nunca se constata a importância do Estado, do setor público, para organizar nossa produção de alimentos, a construção de um projeto para a indústria nacional, garantir a soberania, a sustentabilidade dos biomas, da República, enfim. Retomemos este clássico para sabermos quem somos, para recompormos nosso projeto de unidade nacional, de brasilidade, em tempos de Estado mínimo, fundamentalismo religioso, terra plana e, agora, Coronavírus.

Este livro se articula, portanto, como um convite à leitura do clássico Furtado. Reúne, como já mencionamos acima, textos produzidos nos últimos 30 anos por leitores atentos e privilegiados. Atentos, porque pesquisadores, estudiosos dos problemas brasileiros, vinculados a instituições de prestígio nacional e internacional e que têm a crítica como natureza de ofício; privilegiados, porque conviveram em algum momento da vida pessoal, profissional ou acadêmica com o Celso Furtado. Puderam, além de estudá-lo, ouvi-lo, interagir com ele e testemunhar aquilo que nos parece a principal característica de seu legado: a prova de que teoria e prática são indissociáveis.

A proposta, desde o princípio, não era publicar material inédito, mas, sim, resgatar textos já divulgados em outros espaços (livros, dossiês, periódicos, anais) e criar, para eles, novas oportunidades de divulgação, estimular leituras, discussões e instigar novas interpretações do pensamento furtadiano. Contatamos autores e editores. A acolhida foi generosa e sem restrições. Alguns pediram para reler seus textos. A maioria manteve o original. Outros, refizeram ou atualizaram. E outros, ainda, preferiram escrever um novo texto. $\mathrm{O}$ resultado de cada acordo está registrado em notas de rodapé na abertura de cada capítulo. Quatro artigos, incluindo um do professor Wilson Cano, que morreu pouco antes do fechamento desta coletânea, estão publicados in memoriam.

Desde o final dos anos 1960 que o legado de Furtado é tema de debate, sobretudo em livros. Foi um dos poucos pensadores brasileiros a ter sua obra visitada criticamente, ainda em vida. O sociólogo Francisco de Oliveira, de saudosa memória, talvez tenha inaugurado essa linha de discussão. E com dois títulos: um com ensaios críticos sobre a contribuição intelectual e política de Furtado para as políticas de desenvolvimento do Brasil, incluindo a Sudene (A navegação Venturosa, 
republicado recentemente pela Boi Tempo); e outro para a Coleção Grandes Cientistas Sociais (Editora Ática), concentrando-se, sobretudo, nas contribuições teóricas como as discussões sobre desenvolvimento e subdesenvolvimento.

A partir da obra de Oliveira, várias outras emergiram: Era da Esperança: Teoria e Política no Pensamento de Celso Furtado, organizada por Marcos Formiga e Francisco Sales Gaudêncio e publicada pela Paz e Terra (1995); A grande Esperança em Celso Furtado, organizada por Bresser-Pereira e José Marcio Rego e publicada pela Editora 34 (2001); Nas Sombras do Subdesenvolvimento: Celso Furtado e a Problemática Regional no Brasil, de Anderson César G. T. Pellegrino, publicada pela Editora Alínea (2005); Celso Furtado e o século XXI, organizada por João Saboia e publicada pela Martins Fontes (2006); A atualidade do pensamento de Celso Furtado, organizada por Marcos Costa Lima e Maurício Dias David Lima, publicada pela Francis Editora (2008); 50 anos de Formação Econômica do Brasil: ensaios sobre a obra clássica de Celso Furtado, organizada por Tarcísio Patrício de Araújo, Salvador Teixeira Werneck Vianna e Júnior Macambira, e publicada pelo Ipea (2009); O Pensamento de Celso Furtado e o Nordeste Hoje, organizada pelo Centro Celso Furtado e publicada pela Contraponto (2009); Celso Furtado e o Brasil, organizada por Maria da Conceição Tavares e publicada pela Fundação Perseu Abramo (2010).

O que apresentamos a seguir não é um manual técnico do tipo "para compreender Furtado”, mas, sim, um guia crítico, que não conduz o leitor, necessariamente, por um mesmo caminho, que não embala e entrega uma compreensão pronta, fechada, definitiva da obra desse paraibano de Pombal. No máximo, compartilha pistas, recortes, trajetos inconclusos, projetos em curso e uma avalanche de desafios e questões que nos provocarão ainda por muito tempo, dada a singularidade de sua obra. Por isso, este livro interessa (ao menos pensamos assim) tanto aos que desejam conhecer, quanto aos que pretendem realizar estudos mais aprofundados ou mesmo revisitar a obra de Furtado.

\section{Agenda da Coletânea}

Os textos desta Coletânea estão dispostos seguindo quatro conjuntos temáticos: Identidade (Parte I), Pensamento e Contribuições (Parte II), Desenvolvimento x Subdesenvolvimento (Parte III) e Desenvolvimento Regional (Parte IV). 
O Capítulo que abre a Parte I foi escrito por Rosa Freire d'Aguiar, viúva de Celso Furtado, e traça o 'Perfil Intelectual' do nosso homenageado. Tudo começa no sertão da Paraíba, aonde Furtado nasceu e passou os primeiros 20 anos de sua vida, entre literatura, história, filosofia e ciências sociais. Rosa destaca as grandes influências que marcaram a trajetória intelectual de Furtado (Positivismo, Leituras de Marx e a Sociologia Americana), apresenta momentos chaves de sua vida acadêmica e pública, e destaca, por fim, que a atualidade das suas reflexões resulta da coerência de sua vasta obra no tratamento de temas que permanecem instigantes e na ordem do dia.

O perfil traçado por d'Aguiar é aprofundado, na sequência, com um texto de Tamás Szmrecsányi, de saudosa memória. Para este autor, o fato de Celso Furtado continuar sendo o economista brasileiro mais conhecido e melhor conceituado no mundo deve-se não tanto aos cargos que ocupou no Brasil e no exterior, mas, principalmente, ao interesse e à qualidade dos seus trabalhos científicos e técnicos em áreas tão diversas como História Econômica, Teoria do Desenvolvimento, Política Econômica e o Planejamento. A obra de Furtado, no texto de Szmrecsány, é contextualizada e discutida, a partir de três momentos: primeiros escritos (textos e livros produzidos entre 1950-60), obras da maturidade (1960-1970) e últimos trabalhos (pós 1980).

No capítulo Furtado e a educação pela pedra, entranhada o sociólogo José Luciano Albino Barbosa revisita os temas recorrentes na vida de Furtado: a crítica do subdesenvolvimento, a luta contra as oligarquias nordestinas e a criação da Sudene (Superintendência do Desenvolvimento do Nordeste) como expectativa de transformação de estruturas. O artigo busca elucidar a trajetória de Celso Furtado na "Operação Nordeste", sobretudo na tarefa de criar uma política desenvolvimentista, democrática, baseada na industrialização, na racionalidade política e no planejamento estratégico, em afronta direta às estruturas políticas da Velha República. Para Barbosa, Furtado se tornou uma espécie de Lampião contra os coronéis, porém, sem fuzil e sem cartucheira, mas com as armas da argumentação democrática e da inteligência aguda do economista universal. Em concordância com João Cabral de Melo Neto, o autor identifica, no acerto de contas do menino de Pombal com a história, a criança que teve 'uma educação pela pedra: entranhada'.

No último texto da Parte I (Método e Paixão em Celso Furtado) Luiz Carlos Bresser-Pereira afirma que Furtado não ofereceu apenas 
explicações econômicas para nosso desenvolvimento e subdesenvolvimento: ele situou o Brasil no contexto do mundo, analisou sua sociedade e sua política e ofereceu soluções para os grandes problemas. Para realizar essa tarefa tão ambiciosa quanto frustrante - o Brasil ficou aquém de suas grandes esperanças - o economista paraibano, que tem sua obra marcada pela 'independência de pensamento', usou do método e da paixão. Assim, sua luta pelo desenvolvimento para o Brasil e pela superação do atraso da sua terra natal - o Nordeste - foram realizadas com uma intensidade e uma determinação que só a paixão explica.

A Parte II começa com o artigo Celso Furtado: Fundação e Prospectiva do Desenvolvimento, do professor Cândido Mendes. Segundo ele, a reflexão de Furtado teve a marca "antológica do pensamento praxístico, nascido do aprofundamento, sem cortes, da meditação fundadora que retoma, revê, compara”. De acordo com Mendes, deve-se a Furtado não só a indicação do "norte grosso e ineludível" dos rumos nacionais, como convém "a voz imperiosa dos profetas", mas, também, a insistência em dar à consciência de latinidade um denominador que nos situe em dimensões supracontinentais. $\mathrm{O}$ que ele defendeu e previu como nossa posição relativamente excrescente do universo das globalizações, pela nossa economia de mercado interno no Continente continua ou mesmo se antecipa pela consciência do caráter expropriatório com que a visão de mundo hegemônica se apossa dos inconscientes coletivos à sua volta.

Já Bernardo Ricupero foca sua reflexão na contribuição de Furtado para o pensamento social brasileiro. Em Celso Furtado e o pensamento social brasileiro, Ricupero destaca que a contribuição furtadiana à teoria estruturalista da Cepal foi historicizá-la, mostrando como se estabeleceu, ao longo do tempo, a relação entre colônias e metrópoles, países desenvolvidos e subdesenvolvidos, centro e periferia. O texto chama atenção para a relação de Furtado com obras sobre a formação de nossa sociedade - Formação do Brasil contemporâneo (1942), de Caio Prado Jr., Formação da literatura brasileira (1959), de Antonio Candido, e promove um debate entre o que, no seu entender, aproxima e distancia o autor paraibano de tais obras, sobretudo da de Caio Prado Jr.

A dimensão econômica caracteriza o texto seguinte, Celso Furtado e o pensamento econômico brasileiro, escrito por Guido Mantega, para quem o surgimento e a consolidação do pensamento econômico no Brasil estão indissoluvelmente ligados a Celso Furtado. A obra do pensador paraibano, na compreensão de Mantega, em particular a Formação Econômica 
do Brasil e Desenvolvimento e Subdesenvolvimento, demarca a passagem do pensamento econômico brasileiro da pré-história para a história. Sem negar a importância de obras anteriores como a História Econômica do Brasil (1937), de Roberto Simonsen, ou a História Econômica do Brasil (1945), de Caio Prado Jr., no seu entendimento nenhuma delas conseguiu definir um método analítico e amarrar com tanta pertinência os determinantes da dinâmica econômica brasileira.

Por fim, fechando a Parte II, um artigo do professor Wilson Cano, que poucos dias antes de sua morte, ocorrida em 03/04/2020, relia e fazia ajustes em Principais contribuições de Celso Furtado sobre a História Econômica do Brasil e o período recente, publicado, originalmente, em Cadernos do Desenvolvimento (2018). Não recebemos a última versão e reproduzimos, aqui, in memoriam, o texto tal qual está publicado em Cadernos. Para o professor Wilson Cano, dentre as muitas contribuições de Furtado para a história econômica da América Latina e do Brasil, estão estudos relacionados a alguns dos seguintes temas: distribuição de renda; demanda efetiva, crise e crescimento; estruturas produtivas e de emprego; uso social do excedente; insuficiência de poupança e investimentos decorrente do subdesenvolvimento e da distribuição de renda; tendência ao desequilíbrio externo estrutural; questão regional, nacional, ecologia e subdesenvolvimento; cultura, dependência e subdesenvolvimento.

A Parte III abre uma série de debates instigados pela obra de Furtado. No capítulo Celso Furtado e o processo de desenvolvimento-subdesenvolvido visto da periferia: estruturas, decisões e estratégias, o professor Carlos Antonio Brandão afirma que Furtado quando se refere a desenvolvimento, está tratando da construção de ações políticas desmanteladoras de dinâmicas e estruturas que representam e recrudescem o atraso econômico e político e na realização de decisões estratégicas que logrem engendrar novas trajetórias alternativas. No centro de sua interpretação do processo de desenvolvimento-subdesenvolvimento está um rico arcabouço teórico sobre estruturas, decisões e estratégias, que busca apreender as especificidades da 'condição periférica'. O legado de seu plano de estudos e reflexões nos deixa também uma agenda política de ação: "o ponto de partida do processo de reconstrução que temos de enfrentar deverá ser uma participação maior do povo no sistema de decisões. Sem isso, o desenvolvimento não se alimentará de autêntica criatividade e pouco contribuirá para a satisfação dos anseios legítimos da nação". 
Já o sociólogo Francisco de Oliveira, que trabalhou com Celso Furtado e viveu intensamente a experiência da Sudene, também falecido em 2019, escreveu em Subdesenvolvimento: fênix ou extinção?, que o conceito de subdesenvolvimento como uma formação singular do capitalismo - e não como um elo na cadeia do sequenciamento que vai do não-desenvolvido ao desenvolvido - é uma criação cuja densidade e poder heurístico explicativo da especificidade da periferia latinoamericana só foram plenamente alcançados com os trabalhos da Cepal e, sobretudo, de Furtado. Oliveira escreveu ainda: a teorização da Cepal e de Celso Furtado transformou-se em ideologia no sentido gramsciano, já que passou a orientar a agenda de discussão e as pautas dos programas econômicos dos países da periferia capitalista. A força semântica do conceito tornou-se formidável: os últimos 30 anos da história brasileira e latinoamericana foram gastos, pelas ditaduras militares e pelos organismos internacionais na tentativa de destruí-lo.

A mesma questão é retomada e discutida por Maria da Conceição Tavares em Subdesenvolvimento, dominação e luta de classes. Para ela, Celso Furtado definiu o subdesenvolvimento como um processo histórico particular, resultante da penetração das empresas capitalistas modernas em estruturas arcaicas, constitutivo da expansão desigual do capitalismo. Essa visão, segundo Conceição Tavares, representa um enorme avanço sobre a dicotomia atraso/modernização e, em particular, sobre a visão 'etapista' que predominava nos centros de pensamento hegemônica e, também, no debate acadêmico e político. A abordagem de Furtado coloca em cena o tema da dominação internacional a partir da situação de dependência, recriada permanentemente por meio dos elementos de dependência tecnológica, financeira e cultural que marcam o comportamento das classes dominantes brasileiras e de suas elites dirigentes. Assim, da sua teoria desprende-se uma teoria da dependência, muito antes das versões divergentes - e pretensamente mais acabadas - de Gunder Frank e de Cardoso e Falleto.

Vera Alves Cêpeda, em Capital, Trabalho e Intelligentsia - modernização e desenvolvimento no pensamento de Celso Furtado, afirma que é impossível analisar o processo de constituição e transformação da sociedade brasileira sem discutirmos o problema econômico e o fenômeno histórico do desenvolvimentismo e, neste, a contribuição da obra de Celso Furtado. A situação exponencial da obra de Furtado ampara-se na combinação feliz de três aspectos: o método (que se caracteriza pela 
heterodoxia ou ecletismo intelectual, sob a influência da sociologia do conhecimento de Mannheim); o problema (a questão do atraso, base da interpretação de Furtado sobre a formação do Brasil e que configurou sua primeira grande contribuição intelectual na forma da teoria do subdesenvolvimento); e a proposição (a teoria do subdesenvolvimento vira projeto de desenvolvimento, abrindo a reflexão para o campo dos valores e o universo das proposições políticas).

Para o pesquisador português José Luís Cardoso, um dos principais méritos de Furtado foi o de não assumir a pose de um economista monolítico e convencional. No texto Celso Furtado e as encruzilhadas do desenvolvimento afirma que Furtado cruzou uma diversidade de ciências sociais, mostrando que a ciência econômica não pode ficar alheia, nem ignorar, as contribuições de outros domínios científicos que alargam e enriquecem a compreensão da realidade econômica e social. Segundo ele, a difusão e apropriação da obra furtadiana em território português, inspirou leituras e estratégias de desenvolvimento num país que pertencia a uma outra periferia. Numa encruzilhada tecida entre dois lados do Atlântico, o testemunho de Celso Furtado permite ilustrar a importância que os países sempre atribuem à definição de trajetórias de desenvolvimento, independentemente do nível ou patamar que já tenham alcançado.

No último capítulo da Parte III, El discurso del desarrollo y la nación: Celso Furtado, a proposta de Carlos Mallorquin é observar a maneira como Furtado se engaja na luta "de dentro" do que ele chama de "cataclismo social e político", construindo teoricamente o imaginário social, nem sempre sem contradições políticas e teóricas, dadas suas responsabilidades públicas. A ideia de participação do Estado no processo de modernização da nação, industrialização, reformas estruturais, integração de regiões atrasadas, enfim, o desenvolvimento do país estavam em sua agenda. As desventuras políticas e as reflexões subsequentes conseguem esclarecer que desenvolvimento não pode ser confundido com crescimento. Se o primeiro implica a inclusão da nação invisível, o segundo tende a concentração dos frutos do progresso técnico em uma minoria desnacionalizada.

Abrindo a última parte desta Coletânea (Parte IV), o economista e pesquisador do Cedeplar (UFMG) Clélio Campolina Diniz, em Celso Furtado e o desenvolvimento regional discute os avanços da obra do pensador paraibano para a compreensão e enfrentamento da questão 
regional. Em primeiro lugar, porque supera a noção de região e passa a tratar da estrutura espacial, demonstrando as várias articulações inter e intraterritorial no processo de desenvolvimento; em segundo, introduz o papel do urbano e das cidades na estruturação e no comando do território, cuja importância e complexidade só têm se ampliado nos últimos anos; em terceiro, demonstra que as desigualdades são produtos das formas em que se introduzem e se distribuem as modernas tecnologias; e, por fim, ressalta a complexidade dos fenômenos espaciais, propondo um esforço interdisciplinar como caminho para a formulação de uma teoria das estruturas espaciais. A inovação, segundo Campolina, é que Furtado trabalha sua construção teórica como fundamento e base para a ação política.

No capítulo seguinte, Desigualdades regionais e Nordeste em Formação Econômica do Brasil, Tania Bacelar de Araújo e Valdeci Monteiro dos Santos, procuram explicitar as principais descobertas de Furtado no desafio de interpretar a problemática regional, em especial do Nordeste brasileiro. Começam pelo caminho percorrido por Furtado para chegar à síntese apresentada em $F E B$; investigam o que ele que precisou complementar em suas análises quando o presidente Juscelino Kubitschek o chamou a atuar na vida pública; problematizam a proposta de Furtado para mudar o Nordeste, fundamentada na criação da Superintendência do Desenvolvimento do Nordeste (Sudene) e de sua ação à frente do órgão; e discutem a atualidade da visão de Furtado sobre o Nordeste contemporâneo.

Desenvolvimento, região e poder regional: a visão de Celso Furtado foi um dos últimos textos escritos e publicados pelo professor Hermes Magalhães Tavares, falecido em 2019. Neste artigo Tavares busca recolocar a questão do desenvolvimento regional, na perspectiva macro (econômica e espacial), recorrendo à obra de Furtado, nas dimensões teórica e empírica. Consciente dos problemas que os desequilíbrios econômicos espaciais podem colocar para a nação, Furtado sempre entendeu que a região, no Brasil, deve ser pensada em primeiro lugar em sua dimensão ampla (a grande região). Ao reavivar a lembrança das ideias de Celso Furtado no campo do desenvolvimento regional, enfatiza o professor Tavares, pensamos também em contribuir para a discussão desse tema, em um momento em que tende a se firmar, entre nós, abordagens que acentuam sua ênfase apenas no recorte microespacial (e também microeconômico), como se as dimensões dos países europeus fossem 
equivalentes às do Brasil.

Fechando a Parte IV e também a coletânea, em Celso Furtado: 6o anos do seu legado para a questão regional brasileira (1959-2019), o pesquisador do IPEA Aristides Monteiro Neto destaca que Celso Furtado fez parte de um grupo de intelectuais e profissionais do serviço público que em meados do século XX deu enorme contribuição ao desenho institucional que configurou o Brasil moderno. Propositor de um novo arranjo institucional para a atuação federal na política regional, Furtado deixou um grande legado institucional: a Sudene e sua história de planejamento do desenvolvimento regional. No momento em que o país se encontra numa transição produtiva em direção à desindustrialização e especialização em atividades intensivas em recursos naturais e mão de obra de baixa remuneração, preso numa armadilha de baixa ou média renda per capita, as lições de Celso Furtado tornam-se tanto mais necessárias quanto mais a sociedade brasileira fracassa quando incorre em estratégias repressoras das escolhas coletivas e democráticas.

\section{Otimismo militante}

Se era inquestionável a preocupação de Celso Furtado com o diagnóstico bem feito, com a compreensão acurada da realidade, a partir de seu frequente recurso às relações entre o todo e as partes, se, portanto, lhe era caro o entendimento pormenorizado daquilo que merecia a sua atenção, tampouco cabe dúvida quanto ao seu esforço de elaborar cenários e neles identificar as alternativas mais sensatas e politicamente mais viáveis. Dotado desses recursos - mesmo obrigado a viver e a trabalhar por um tempo considerável longe de seu país - ele se faria tão presente no debate público, com sua obra engajada e provocativa, a ponto de, no início da década dos anos 1980, Francisco de Oliveira (1983, p. 27) afirmar que “... não se conhece nenhum outro autor contemporâneo cuja influência no Brasil tenha alcançado os níveis que a obra de Furtado alcançou" (ver, também, a introdução deste texto).

O que, pois, ainda merece consideração é, precisamente, este "olhar para a frente" de Celso Furtado, que - como, aliás, seu empenho em decifrar o presente - seria, desde cedo, temperado por um conjunto de valores éticos quase idiossincraticamente furtadianos. Ou seja: tratavase de "olhar para a frente", mas armado com algo transcendente, que ia além, digamos, do mero "desenvolvimento". E, por surpreendente que possa parecer, isso se manifesta realmente cedo em Furtado, não apenas 
nas conhecidas obras dos últimos anos de vida em que vai fazendo os balanços e avaliações das questões que o ocuparam, enfim, de sua trajetória intelectual e política.

Uma das ocasiões em que explicitou essa preocupação foi durante a 31를 Reunião Anual da Sociedade Brasileira para o Progresso da Ciência, realizada, em 1979, em Fortaleza, lembrando ao público ser "indispensável que os cientistas vejam naquilo que eles produzem valores, algo que tem um sentido em si mesmo, que está relacionado com os fins da vida humana. Produzir valores implica ter consciência do contexto social em que vivemos..." (FURTADO, [1979] 2013, p. 486).

E a quais valores se referia Celso Furtado? Ao distinguir meios e fins, tinha consciência de que haveria algo realmente transcendente a que se deveria subordinar o esforço do desenvolvimento. Em inúmeras oportunidades, aludiu, por exemplo, a liberdade, republicanismo, solidariedade, humanismo e equidade. Mas, não só. Parece emblemático, a propósito, o seguinte começo de parágrafo: "É sobre essa tela de fundo de autodeterminação e consciência de responsabilidade que devemos projetar os objetivos irredutíveis da ação política" (FURTADO, 1962, p. 19). Estas preciosas linhas encontram-se no primeiro capítulo de $A$ pré-revolução brasileira, livro originalmente publicado no ano de 1962. Nessas duas linhas expressa sua preocupação com o "agir para dentro do futuro" e, ao mesmo tempo, informa sobre quais valores ela se assenta.

A rigor, compreender a realidade com a seriedade dos melhores métodos para modificá-la com as melhores intenções em direção a algo material e espiritualmente melhor é, para empregar um valor-comum, uma constante em Celso Furtado. Fê-lo desde cedo e nunca mais deixou de fazê-lo. Por exemplo, ao referir-se à "luta contra o subdesenvolvimento", Celso Furtado (1992b, p. 19) vaticinou: "Somente um projeto político apoiado em conhecimento da realidade social poderá romper a sua lógica perversa”.

O que, talvez, seja mais destacável, pelo menos, da ótica de seus leitores, é o "olhar para a frente" como um tema de maior presença em seus últimos escritos e reflexões. Como e em que circunstâncias ele aparece? Uma pista: nas suas análises sobre as possibilidades do Brasil como nação, sobre o projeto nacional brasileiro. Com efeito, em Brasil: a construção interrompida, Celso Furtado (1992a, p. 35) se pergunta “... se temos um futuro como nação que conta na construção do devenir humano. Ou se prevalecerão as forças que se empenham em interromper o 
nosso processo histórico de formação de um Estado-nação”. É, portanto, nesse contexto de suas reflexões sobre o projeto nacional, sobretudo, nos últimos anos de sua vida, que o "olhar para a frente" emerge com maior frequência.

A dúvida que Celso Furtado expressa em relação às possibilidades do Brasil "na construção do devenir humano" é encarada, quase sempre, com o que, inspirado em Ernst Bloch, chamaria de "otimismo militante". Mas, também há momentos de fria consideração de condicionantes e, inclusive, de aberto pessimismo. No primeiro caso, da dúvida que se converte em condicionante, vale lembrar do que Celso Furtado via como restrições à redemocratização (que se descortinava em fins dos anos 1970) e que - desafortunada coincidência - faz grande sentido para os tempos presentes:

\begin{abstract}
O processo político nos próximos anos e as opções válidas que se apresentarão às forças que pretendem intervir nesse processo, serão certamente condicionadas pelo comportamento do grupo militar que controla atualmente o aparelho do Estado. Para penetrar no comportamento desse grupo, seguramente nenhum teste é tão importante como o de suas reações em face do assédio das forças imperialistas visando a desacreditar a ideia de um projeto nacional brasileiro (FURTADO, 1979, p. 20).
\end{abstract}

No segundo caso, da dúvida que se traveste de aberto pessimismo, Celso Furtado expressa seu desencanto com a política econômica do governo FHC que, a pretexto de gerir o Plano Real, promove a privatização do patrimônio público, a desnacionalização do capital privado brasileiro, os ganhos especulativos, o colapso das contas externas, a concentração dos rendimentos e desemprego em escala até então desconhecida. Neste momento confessou: "Em nenhum momento de nossa história foi tão grande a distância entre o que somos e o que esperávamos ser" (FURTADO, 1999, p. 26).

Se os momentos citados destoam de seu "otimismo militante", o "olhar para a frente" de Celso Furtado não considerava o futuro, de nenhum modo, um lugar para o qual se poderia ingressar sem transtornos. Havia grandes desafios a enfrentar - advertia - para os quais seria necessário preparar a nova geração: "se trata, por um lado, de preservar a herança histórica da unidade nacional e, por outro, de continuar a construção de uma sociedade democrática aberta às relações externas" (FURTADO, 2001, p. 429). 
Este ponto parece crucial por que Celso Furtado parte da "herança histórica da unidade nacional", que é, simultaneamente, um ativo a partir do qual se poderiam fazer novas conquistas e, se e quando necessário, impor-se diante das demais nações; e uma totalidade (expressa, por exemplo, no território e/ou na população) que contém elementos (a língua, a literatura, as artes...) que tanto valorizaria a partir de suas reflexões sobre a questão da cultura. Se, porém, parte da herança, mira a sociedade democrática - que precisa ser construída! Está aí, pois, a utopia em Celso Furtado. Aliás, sua compreensão era de que “... o utópico muitas vezes é fruto da percepção de dimensões secretas da realidade, um afloramento de energias contidas que antecipa a ampliação do horizonte de possibilidades aberto a uma sociedade" (FURTADO, 2002, p. 36-37). Essa foi a forma como processara a devastação fernandina e, erguendo o queixo, relançava altivo - pela enésima vez? - o seu "olhar para a frente" em busca do horizonte de possibilidades.

E o que deveria ser retido, como lição última desta figura humana tão singular que foi Celso Furtado, sobretudo, por quem está acabando de chegar? Prestar atenção, muita atenção, em sua voz calma e já cansada, mas que ainda se pode escutar, ao proclamar, na ocasião da outorga do título de doutor honoris causa pela UFRJ,: "Equivoca-se quem pretende que já não existe espaço para a utopia. Esse é o desafio maior que enfrenta a nova geração: convido-a a assumi-lo sem temores" (FURTADO, [2002] 2013, p. 457).

\section{Referências}

ARAÚJO, Tarcisio Patricio de; VIANA, Salvador Teixeira Werneck; MACAMBIRA, Júnior (Orgs.) 50 anos de Formação Econômica do Brasil: ensaios sobre a obra clássica de Celso Furtado. Brasília: Ipea, 2009.

BRESSER-PEREIRA, Luiz Carlos; REGO, José Marcio (Orgs.). A grande Esperança em Celso Furtado. São Paulo: Editora 34, 2001.

CENTRO CELSO FURTADO. O Pensamento de Celso Furtando e o Nordeste Hoje. Rio de Janeiro: Contraponto, 2009.

CEPÊDA, Vera Alves. O pensamento político de Celso Furtado - desenvolvimento e democracia. In: BRESSER-PEREIRA, Luiz Carlos; REGO, 
José Marcio. (Orgs.). A grande esperança em Celso Furtado. São Paulo: Editora 34, 2001, p. 167-184.

FORMIGA, Marcos; GAUDÊNCIO, Francisco Sales (Orgs.). Era da Esperança: Teoria e Política no Pensamento de Celso Furtado. São Paulo: Paz e Terra, 1995.

FURTADO, Celso. A pré-revolução brasileira. Rio de Janeiro: Ed. Fundo de Cultura, 1962.

FURTADO, Celso. Brasil: da República Oligárquica ao Estado Militar. In: FURTADO, Celso et al. Brasil: Tempos Modernos. 3 ed. Rio de Janeiro: Paz e Terra, p. 1-23, 1979.

FURTADO, Celso. Ciência para quê e para quem? In: D’AGUIAR, Rosa Freire (Org.) Essencial Celso Furtado. São Paulo: Penguin Classics; Companhia das Letras, p. 482-487, [1979] 2013.

FURTADO, Celso. Brasil: a construção interrompida. Rio de Janeiro: Paz e Terra, 1992a.

FURTADO, Celso. O subdesenvolvimento revisitado. Economia e Sociedade, N. 1, p. 5-19, 1992 b.

FURTADO, Celso. O longo amanhecer: reflexões sobre a formação do Brasil. Rio de Janeiro: Paz e Terra, 1999.

FURTADO, Celso. Quando o futuro chegar. In: SACHS, Ignacy; WILHELM, Jorge; PINHEIRO, Paulo Sérgio (Org.) Brasil: um século de transformações. São Paulo: Companhia das Letras, p. 418-429, 2001.

FURTADO, Celso. Em busca de novo modelo: reflexões sobre a crise contemporânea. 2 ed. Rio de Janeiro: Paz e Terra, 2002.

FURTADO, Celso. Metamorfoses do capitalismo. In: D’AGUIAR, Rosa Freire (Org.) Essencial Celso Furtado. São Paulo: Penguin Classics; Companhia das Letras, p. 450-457, [2002] 2013. 
LIMA, Marcos Costa; DAVID LIMA, Maurício Dias (Orgs.). A atualidade do pensamento de Celso Furtado. Brasília: Editora Francis, 2008.

MELO NETO, João Cabral. A educação pela pedra: Rio de Janeiro: Nova Fronteira, 1996.

OLIVEIRA, Francisco de. Introdução: a navegação venturosa. In: OLIVEIRA, Francisco de (Org.) Celso Furtado: economia (= Grandes Cientistas Sociais, 33). São Paulo: Ática, p. 5-29, 1983.

PELLEGRINO, Anderson César. Nas Sombras do Subdesenvolvimento: Celso Furtado e a Problemática Regional no Brasil. Campinas: Alínea, 2005 .

SABOIA, João (Org.). Celso Furtado e o século XXI. São Pulo: Martins Fontes, 2006.

TAVARES, Maria da Conceição (Org.). Celso Furtado e o Brasil. São Paulo: Fundação Perseu Abramo, 2010.

Brasil, abril de 2020 